\title{
Pharmacogenetic Tools for the Development of Target-Oriented Cognitive-Enhancing Drugs
}

\author{
José A. Apud and Daniel R. Weinberger \\ Genes, Cognition and Psychosis Program, Clinical Brain Disorders Branch, National Institute of Mental Health, \\ National Institutes of Health, Health and Human Services, Bethesda, Maryland 20892
}

\begin{abstract}
The identification of the anatomical and physiological substrates involved in the regulation of the dorsolateral prefrontal cortex function in humans provided the basis for the understanding of mechanisms involved in cognitive and executive function under normal as well as pathological conditions. In this context, substantial evidence indicates that alterations in monaminergic function in the dorsolateral prefrontal cortex significantly contributes to the cognitive impairments present in schizophrenia, attention deficit disorders, and other neuropsychiatric conditions. The development of a number of compounds that selectively increase extracellular dopamine (DA) concentrations in the dorsolateral prefrontal cortex but not in subcortical areas by either blocking its metabolism or reuptake, or increasing its release, or that directly activate postsynaptic DA-1 receptor mechanisms provided powerful pharmacother-
\end{abstract}

apeutic tools to mitigate the cognitive deficits brought about by the dopaminergic alterations of the prefrontal cortex. More recently, the findings that polymorphisms of the catecholamine$O$-methyl-transferase gene may also modify the effect of these drugs on the prefrontal cortex points toward a more specific genotype-based neuropsychopharmacology for the treatment of cognitive deficits in schizophrenia as well as in a number of other neuropsychiatric conditions. The ability of these compounds to increase DA load selectively in the frontal cortex and not on subcortical systems allows a targeted intervention without the stimulant-like effects observed with older drugs used to treat those conditions. Key Words: Dorsolateral prefrontal cortex, dopamine, schizophrenia, attention deficit disorder, dopamine- 1 receptors, Tolcapone, Modafinil, Atomoxetine, DAS431.

\section{INTRODUCTION}

A growing body of evidence supports the notion that the dorsolateral prefrontal cortex (DLPC) plays a major role in a number of cognitive processes including executive function, learning, nonverbal memory, vigilance, and attention among others. ${ }^{1-4}$ Because prefrontal cortex dysfunction is a frequent concomitant of psychiatric disorders, cognitive deficits in such patients are common and prevent them from maintaining or developing new skills necessary for reintegration into community life. The DLPC is innervated by a number of neurotransmitters systems and modulators that have been popular targets for drug development, mainly the monoaminergic system. ${ }^{5,6}$ Disruption of the mesocortical dopaminergic

Address correspondence and reprint requests to Jos, A. Apud, Genes, Cognition and Psychosis Program, Clinical Brain Disorders Branch, National Institute of Mental Health, National Institutes of Health, Health and Human Services, 10 Center Drive, CRC 7-3342, Bethesda, MD 20892. E-mail: apudj@mail.nih.gov.
(Me-DA) system, a premier catecholaminergic pathway involved in the regulation of frontal lobe function, ${ }^{7}$ leads to impairments in executive function and other cognitive difficulties. A primary defect in the Me-DA system may, in turn, lead to a number of compensatory modifications in interconnected pathways ${ }^{8,9}$ resulting in functional changes in brain areas subserved by those interrelated neuronal systems. Over the last few years, pharmacological strategies pointing toward treatment of cognitive deficits in psychiatric disorders have been pursued. Historically, stimulants such as amphetamines and methylphenidate were shown to affect cognitive function both in experimental animals ${ }^{10}$ and in humans ${ }^{11}$ by increasing extracellular dopamine (DA) and norepinephrine concentrations through presynaptic neurotransmitter release or reuptake blockade. ${ }^{12,13}$ More recent evidence indicates that atypical antipsychotics are able to improve cognitive function ${ }^{14-17}$ in patients with schizophrenia, possibly related to the serotonin (5-HT) 2 a receptor blocking properties of these agents. The blockade of 5-HT 2 a receptors induces an activation of the dopami- 
nergic neurons projecting to the DLPFC with ensuing increase in extracellular dopamine concentrations. ${ }^{18}$

Another strategy for improving cortically mediated cognition, this one based on the proposed role of glutamate on schizophrenia, has been the use of glutamatergic agonists to facilitate NMDA transmission and target cognitive symptoms in patients with schizophrenia. Early trials with NMDA agonists such as D-cycloserine and milacemide, produced mixed results on cognition including positive effects ${ }^{19}$ or no effects. ${ }^{20-22}$ The new generation of glutamatergic drugs acting on the AMPA-type receptor such as the AMPAkines seems more promising. In fact, the AMPAkine receptor agonist CX516 improves cognitive abilities both in humans and experimental animals. ${ }^{23}$ In the last few years, there has been a mounting interest in the contribution of gene polymorphisms in the efficiency of response with which cognition-enhancing drugs improve cognitive function in humans and experimental animals. In this context, catecholamine- $O$-methyltransferase (COMT) and brain-derived neurotrophic factor (BDNF) represent major genes of interest for the field.

In the present review, we will focus on new pharmacotherapeutic approaches in psychiatry involving the dopaminergic system in the prefrontal cortex and genotypebased targeted pharmacology.

\section{THE DOPAMINERGIC INNERVATION OF THE PREFRONTAL CORTEX}

The use of anti-TH antibodies provided a powerful tool to selectively identify dopaminergic terminals in the dorsolateral prefrontal cortex both in monkeys and human samples. ${ }^{5}$ At odds with the dopaminergic innervation in rodents, in the mammalian neocortex, dopaminergic neurons are widely distributed in every cortical region. Interestingly, the distribution of these terminals indicates preferential innervation of motor over sensory regions, sensory associations over primary sensory regions, and auditory associations over visual associations. ${ }^{6}$ Gradients of distribution show that, in the dorsomedial convexity of the frontal lobe, fiber density increases in a rostral to caudal manner from the prefrontal to the premotor region. Additionally, the medial cortical surface displays a ventral to dorsal gradient of increasing fiber density. The laminar distribution of TH-containing terminals showed that lightly innervated areas of the human prefrontal cortex tend to have fibers distributed in a bilaminar manner, whereas the more densely innervated regions such as the dorsomedial region have a more uniform distribution. $^{6}$

Dopamine neurons in the ventral tegmental area provide a critical modulatory role on behavior (facilitation of reward seeking) and cognition. ${ }^{24,25}$ The DA neuron projections to the DLPFC regulate cognitive processes including executive functions, planning and atten- tion. ${ }^{26,27}$ Although there is some controversy about their functional properties, the Me-DA system is believed to have a faster firing rate, have more action potentials in bursts, higher dopamine turnover, ${ }^{28}$ and exhibit enhanced sensitivity to stress ${ }^{29,30}$ when compared with the mesolimbic and nigrostriatal dopamine systems. Also, at odds with other forebrain areas, in the Me-DA system terminals, dopamine exhibits greater extrasynaptic diffusion and slower clearance. ${ }^{31,32}$ Furthermore, transcerebral dialysis studies showed that the ratio of DA in the dialysate is considerably higher in the DPLFC than in the striatum and the accumbens, suggesting that a proportionally greater amount of extracellular DA relative to intraneuronal sites. ${ }^{31,33}$ Factors affecting dopamine synthesis, autoreceptor density, and other features have been ascribed as possible factors to explain these findings. ${ }^{34,35}$ Studies on mice lacking dopamine transporter (DAT) gene expression, however, indicated that those factors had less impact on extracellular dopamine accumulation than the DAT protein itself. ${ }^{36}$ Thus, the lack or paucity of DATs in the cortical synaptic cleft may provide a rational explanation to understand the higher extracellular dopamine concentrations and greater diffusion space at the level of the Me-DA system terminals when compared with the mesolimbic or nigrostriatal systems. The limited efficacy of dopamine reuptake blockers in the DLPFC when compared with other dopaminergic areas further substantiates this view. ${ }^{37-39}$

A number of studies aiming at identifying the mechanism(s) by which the DPLFC terminate the actions of dopamine revealed that reuptake by the norepinephrine transporter (NET) diffusion, as well as enzymatic processing, are responsible for eliminating DA from the cortical synaptic cleft. ${ }^{33,39,40}$ Both in vivo and in vitro evidence indicates that extracellular DA in the DLPFC is cleared primarily by NET mechanisms. In a cerebral dialysis model, studies using the norepinephrine (NE) inhibitor desipramine revealed that this compound elevates both DA and NE levels in the prefrontal cortex, an area where the NET is more concentrated than the DAT. ${ }^{37,41}$ Furthermore, in vitro studies using a knockout mice model for the NET further confirmed that the uptake of DA in the frontal cortex depends primarily on the NET. $^{42}$

A second mechanism by which DA is cleared form the DLPFC, in this case a volume diffusion mechanism, has been more recently identified. "Volume" transmission refers to three-dimensional signal diffusion within the brain extracellular fluid. Volume transmission includes short- $(\sim 20 \mathrm{~nm})$ and long-distance diffusion of signals through the extracellular and CSF. The slow uptake of DA in the DLPFC, apparently due to the low density of NET when compared with other brain areas, enables diffusion over dimensions approaching $100 \mathrm{æm}^{43,44}$ This diffusion increases the likelihood of volume trans- 
mission, with subsequent catabolism of DA by different means, including an extrasynaptic DAT mechanism, in an area far from the original synapse where the release took place.

A third mechanism by which the action of DA is terminated in DLPFC involves the enzyme COMT (EC 2.1.1.6). COMT is a ubiquitous enzyme that catalyzes the transfer of a methyl group from substrates carrying the catechol moiety ${ }^{45}$ and plays a critical role in the metabolism of catecholamine neurotransmitters such as dopamine, adrenaline, and noradrenaline. The structures of the two isoforms of COMT and the gene were characterized almost 15 years ago. ${ }^{46-48}$ Both rat and human soluble (S)-COMTs contain 221 amino acids, and the molecular masses are 24.8 and $24.4 \mathrm{kDa}$, respectively. The human S-COMT peptide sequence is about $81 \%$ identical to the rat enzyme. ${ }^{49,50}$ The respective molecular masses of membrane-bound COMT are 29.6 and 30.0 $\mathrm{kDa}$. One single gene was found for COMT, which encodes both the soluble and membrane-bound COMT. ${ }^{46,48}$ Using in situ hybridization and cell hybrid techniques, the COMT gene in humans was localized in chromosome 22, band q11.2. ${ }^{51,52}$ Early pharmacological studies $^{40}$ revealed that the catabolic flux of synaptic dopamine through the COMT pathway is much greater in the prefrontal cortex as compared to other brain DA pathways. More recent studies in the COMT knockout mice, when compared with the wild-type mice, revealed that DA concentrations are increased in the DLPFC but not in the striatum. ${ }^{53,54}$ Our group has also shown that COMT mRNA is expressed primarily in neurons in the prefrontal cortex in both rodent and human tissue. Furthermore, COMT mRNA concentrations in the DLPFC are significantly higher than in the striatum of both species. ${ }^{55}$ The high levels of COMT and the lack or scarcity of DAT at synapses in the DLPFC most likely contribute to the relative functional specificity for COMT to prefrontal DA metabolism. In contrast, in the striatum, the very efficient dopamine neuronal uptake mechanism terminates the synaptic action of dopamine and COMT plays little functional role. ${ }^{31,36,56-59}$

The level of COMT enzyme activity is genetically polymorphic in human red blood cells and liver, with a trimodal distribution of low, intermediate, and high levels of activity. ${ }^{60-63}$ This variation is largely explained by a single-nucleotide polymorphism at base 158 in the COMT gene. This genetic polymorphism results in substantial, three- to four-fold differences in COMT activity in red blood cells and liver, ${ }^{60,62}$ which may explain individual variation in metabolism of catecholamines and catecholaminergic drugs. ${ }^{64-66}$ In postmortem DLPFC, however, determination of COMT activity using standard laboratory methods revealed that, in human subjects, the activity of the COMT-Val allele is approximately $40 \%$ higher and shows higher thermostability at $37^{\circ} \mathrm{C}$ than the COMT-Met allele. Similar results were confirmed in human lymphocytes under the same experimental conditions, indicating that the findings in postmortem tissue are not artifacts of potential differences in postmortem protein stability based on genotype. ${ }^{67}$

\section{GENES AND DOPAMINE MODULATION OF PREFRONTAL COGNITIVE FUNCTION}

Neuropharmacological intervention with monoaminergic drugs in healthy subjects can have an individualspecific response. A psychopharmacological study with bromocriptine (a D2-receptor agonist) ${ }^{68}$ reported improvement in performance of a visuospatial working memory task only in subjects with lower working memory capacity. On the other hand, subjects with high capacity performed more poorly on the drug. They suggested that these population differences (subjects with high $v s$ low working memory capacity) might be related to different (high vs low) endogenous metabolism of dopamine. This notion is consistent with monkey studies that examined dose-response relationships and can be summarized as biphasic effects of D1 antagonists, with low-dose facilitation and medium- to high-dose impairment ${ }^{10,69-72}$ and triphasic effects of D1 (and D2) agonists, with low-dose impairment, medium-dose facilitation, and high-dose deterioration. ${ }^{10,71,72}$ Consistent with the findings of Kimberg et al., ${ }^{68}$ it was observed in six subjects performing the N-Back working memory task that dextroamphetamine improved performance only in those subjects that had relatively low working memory capacity at baseline. In the subjects that had high working memory capacity at baseline, performance deteriorated on amphetamine. ${ }^{73}$

It is possible that these population differences in working memory capacity (high $v s$ low working memory capacity) and the differential affects of dopamimetics may be related to allelic variation of dopamine system genes, e.g., COMT enzyme activity with resulting variation (high $v s$ low) in extracellular concentrations of catecholamines. In this line, we have recently found that this polymorphism in the COMT gene accounts for $4 \%$ of the variance in performance of working memory tasks in humans. ${ }^{74,75}$ The val allele produces the high-activity enzyme, which presumably breaks down synaptic dopamine more rapidly compared to the met allele, resulting in lower dopaminergic activity at critical synapses in the prefrontal cortex. Subjects with the val/val genotype have relatively impaired performance relative to met/met subjects, both in normal controls and schizophrenic patients. This genetic finding is consistent with prior data in animals showing a region-specific effect of COMT activity in prefrontal dopamine metabolism ${ }^{53}$ and that COMT knockout animals have improved working memory. ${ }^{76}$ 
The COMT gene polymorphism findings suggest that increasing the availability of DA in the DLPFC either by decreasing DA metabolism through COMT inhibition, by reducing DA reuptake through blockade of noradrenaline (NA) reuptake sites, or by increasing DA release, particularly in subjects with the val/val genotype, will most likely improve working memory and prefrontal efficiency both in normal individuals and in patients with other cognitive difficulties including schizophrenia, attention deficit problems, and dementing processes.

\section{COMT INHIBITORS AND DLPFC FUNCTION}

In the last few years, a number of compounds with inhibitory activity on COMT were discovered. ${ }^{77}$ Among them, tolcapone ${ }^{78,79}$ proved to be the most potent in vitro and can penetrate the blood brain barrier. Tolcapone inhibits brain COMT activity in vivo with an $\mathrm{ID}_{50}$ value of $26-28 \mathrm{mg} / \mathrm{kg}^{2,80}$ More recently, PET studies also have shown that tolcapone acts as a central COMT inhibitor in Parkinson's disease. ${ }^{81,82}$ Tolcapone seems to be a quite specific inhibitor of COMT because it neither affects the reuptake of tritiated amines nor interacts with neurotransmitter receptors. ${ }^{78-80}$ In behavioral studies, intraperitoneal administration of tolcapone after pretraining facilitated spatial working memory in intact rats. Similarly, tolcapone improved the performance of senescent poor performers in the spatial memory task but was unable to counteract memory performance deficits in rats treated with scopolamine. ${ }^{83,84}$ These data suggest that tolcapone may improve some aspects of cognition, in particular working memory, by reducing dopamine catabolism in the prefrontal cortex.

Clinical studies showed that tolcapone decreases COMT activity and increases L-dopa availability when both compounds are given in combination. ${ }^{85,86}$ Interestingly, the addition of tolcapone to L-dopa improved function in attentional tasks, auditory verbal short-term memory, visuo-spatial recall, and constructional praxia. ${ }^{84,87}$ Tolcapone by itself was also effective for the treatment of major depression. Tolcapone by itself was also effective for the treatment of major depression.

In normal volunteers, we have recently found tolcapone effects and genotype effects on measures of cognitive function. Tolcapone significantly enhanced performance in normal subjects on tasks that demand speed of response in the context of working memory, namely Trails $B$ (in which the sequencing of letters and numbers proceeds in alternating manner) and $N$ Back at high loads (in which updating of the working memory buffer is near continuous). ${ }^{88}$ For ID shifting from the CANTAB test battery, and episodic memory tasks, the response to tolcapone was modulated by COMT genotype. In the ID shifting test, a task that requires rule generalization in the face of a salient distractor, a significant drug $\times$ genotype interaction was present, such that individuals with val/val genotypes markedly improved while receiving tolcapone, whereas individuals with met/met genotypes worsened. A genotype effect was also observed in verbal episodic memory tests in which individuals with val/val genotypes markedly improved, although not statistically significant, while receiving tolcapone, whereas individuals with met/met genotypes worsened. These results are consistent with previous studies on cognitive tasks in which dextroamphetamine, a drug that releases dopamine from nerve terminals, improved performance only in those subjects that had relatively low working memory capacity at baseline (val/val). In the subjects that had high working memory capacity at baseline (met/met), performance deteriorated on amphetamine. ${ }^{73}$ An effect of tolcapone on the physiologic response during working memory was also observed on functional magnetic resonance imaging (fMRI) studies. In fact, tolcapone improved DLPFC efficiency in normal volunteers without observing overall significant genotype by drug effects on fMRI-based efficiency measures. ${ }^{89}$

\section{MODAFINIL AND DLPFC FUNCTION}

The psychoactive drug modafinil is an agent marketed for the treatment of excessive day sleepiness associated with narcolepsy, sleep apnea, and idiopathic hypersomnia. ${ }^{89-92}$ The mechanism of action of modafinil has not yet been clearly identified but several studies have shown an interaction with $\alpha_{1}$ adrenergic receptors and with DAergic, GABAergic and glutamatergic transmission mechanisms. ${ }^{93-96}$ Recent studies showed that modafinil increases dopamine release at wake-promoting doses through an action on the dopamine transporter (DAT). In fact, homozygous DAT knockout mice were shown to be unresponsive to the normally wake-promoting effect of modafinil and methamphetamine but were hypersensitive to the wake-promoting effects of adenosine receptor antagonist caffeine. ${ }^{96,97}$

Microdialysis studies in the rat ${ }^{98}$ showed a significant increase in extracellular DA, 5-HT, and NA in the prefrontal cortex following modafinil administration. The increase of extracellular NA in the prefrontal cortex, however, was shorter lasting and lower when compared with the increase in extracellular DA and 5-HT in the same area. The higher levels of DA in the frontal cortex may indicate that, in part, dopaminergic neurotransmission in the prefrontal cortex mediates the pharmacological effects of modafinil. ${ }^{96}$ In turn, the increase in synaptic DA in the prefrontal cortex after modafinil may be responsible for the therapeutic effects of this drug on cognitive function. In fact, administration of modafinil in normal mice induces a dose-dependent improvement short-term working memory without changes in explor- 
atory latencies or in activity in a four hole-board apparatus. ${ }^{98}$

Neuropsychological studies in normal volunteers revealed that Modafinil at a dose of $100-200 \mathrm{mg} / \mathrm{d}$ significantly improved the performance in tests of digit span, visual pattern recognition memory spatial planning and stop-signal reaction, and a slowing in latency on delayed matching to sample and the spatial planning task. In these studies, however, no effect of modafinil was observed on spatial memory span, attentional shifting or spatial working memory. ${ }^{99,100}$

Recent studies on modafinil and narcolepsy found an association between COMT genotype and narcolepsy. This association, however, was observed only on measures of narcolepsy severity and were dependent on gender. In fact, female narcoleptics with the met/met genotype were less severely affected and also responded to lower doses of modafinil. ${ }^{101}$ In line with the investigations on COMT polymorphisms and cognition, ${ }^{74}$ it could be proposed that the effect of Modafinil on working memory and other neurocognitive tests may be associated with a specific COMT polymorphism. The ability of modafinil to raise DA concentrations in the prefrontal cortex and to improve working memory in experimental models raises the question of whether administration this drug in humans will improve working memory and physiological efficiency of the prefrontal cortex in a manner similar to that induced by COMT inhibitors and whether this effect may be genotype dependent. If this were the case, it could be hypnotized that the most prominent effect of modafinil will be observed in subjects bearing the val/val genotype in which the high COMT activity in the DLPFC keeps synaptic dopamine levels at a concentration lower than those bearing the met/met genotype. Initial investigations are being performed in normal volunteers and patients with schizophrenia to test this hypothesis.

\section{SELECTIVE NOREPINEPHRINE REUPTAKE BLOCKERS AND DLPFC FUNCTION}

In the last few years, a series of studies were designed to elucidate how norepinephrine reuptake inhibitors work and exert their therapeutic action on the prefrontal cortex. Among these compounds, atomoxetine was found to be effective for the treatment of attentional problems related to attention deficit disorder (ADD) with or without hyperactivity. ${ }^{102}$ The precise mechanism by which atomoxetine improves ADD is not totally fully understood, although it is thought to be related to selective inhibition of the presynaptic NET, as determined by neuronal uptake and transmitter depletion studies. ${ }^{103}$ Blockade of the NET increases extracellular levels of NE and DA in the prefrontal cortex, a region involved in attention and memory ${ }^{104}$ without modifying DA levels in other areas such as the accumbens or the striatum where NE terminals are scarce. ${ }^{105}$ The ability of atomoxetine to improve attentional deficits problems without activating the mesolimbic or nigrostriatal DA pathways explains the lack of a psychotomimetic effect or abuse potential of this drug. ${ }^{106}$

The capacity of norepinephrine reuptake blockers (NRIs) to enhance dopamine neurotransmission in the frontal cortex provides a rational base to use atomoxetine for the treatment of attention difficulties. ${ }^{102}$ Historically, stimulant medications have been used for the treatment of cognitive difficulties associated with attention deficit disorders. There is general consensus that, similar to NRIs, stimulants modulate attention by potentiating monaminergic activity in the DLPFC. ${ }^{107}$ However, they also increase dopamine output in other brain areas inducing motor and affective changes as well as increasing the potential for drug abuse. Recent studies showed that stimulants, namely amphetamine, enhanced the efficiency of the DLPFC function assayed with fMRI during an N-Back, working memory task. ${ }^{108}$ Interestingly, this effect seemed to be associated with a COMT (val158met) polymorphism. In subjects with the high enzyme activity val/val genotype, which presumably have relatively less prefrontal synaptic dopamine, amphetamine significantly increased DLPFC efficiency at all levels of N-Back load. In contrast, in subjects with the low activity met/met genotype who perform better on baseline prefrontal working memory tasks, the drug had no effect on cortical efficiency at low-to-moderate working memory load and caused deterioration at high working memory load. ${ }^{108}$

The possibility that NRIs such as atomoxetine may be able to 1) improve cognitive functions other that attention deficit disorder and, 2) discriminate this effect through a COMT polymorphism related mechanism merits investigation. Enhanced dopaminergic output in the DLPFC may improve attentional difficulties possibly through indirect activation of DA-1 receptors known to modulate working memory and other executive functions. ${ }^{109}$ Atomoxetine, as well as other potential NRIs, hold some potential as cognitive enhancers because of their ability to target very specifically prefrontal cortex dopaminergic neurotransmission.

\section{DOPAMINE-1 AGONISTS AND DLPFC FUNCTION}

Dopamine activity at D1 receptors mediates many of the cognitive processes subserved by the prefrontal cortex (PFC) discussed above, particularly working memory. Anatomical data indicates that the D1 receptor is the most abundant dopaminergic receptor in the mammalian PFC. ${ }^{110}$ Indeed, medications that directly activate the D1 receptor may remediate cognitive deficits in rats enhanc- 
ing the accuracy of attentional performance and the speed of making correct responses. ${ }^{111}$ By contrast, the use of dopaminergic antagonists, especially those more selective for the D1 receptor such as SCH23330, worsens performance in attentional tasks and in the delayed response paradigm. ${ }^{110-112}$

Based on the above data, it is also reasonable to approach the therapeutics of cognitive dysfunction by directly stimulating the D1 receptor in the PFC. Although D1 receptor agonists are in experimental phase, one clinical trial has taken place in patients with schizophrenia using the selective partial D1 agonist SKF-38393. Interestingly, in line with previous findings using amphetamine, ${ }^{113}$ about one third of the patients had an improvement in perseverative errors in the WCST, whereas the other two thirds had a worsening of the perseverative errors, ${ }^{114}$ suggesting the possibility that the effect of direct DA-1 agonists on cognitive function may be also mediated through a genotype-mediated event. Another promising drug is dihydrexidine, a selective and full D1 agonist that is being developed for the treatment of Parkinson's disease. Animal studies have demonstrated cognitive enhancing properties of this drug, ${ }^{115}$ which appear mediated by D1 activation and by interaction with the cholinergic system.

In the last few years, a new class of D1 agonists typified by ABT-431 (DAS-431), with long-term solidstate stability, was synthesized. ${ }^{116}$ DAS-431 is fully converted to A-86929 rapidly by nonspecific plasma esterases with a $t_{1 / 2}$ of less than 60 s. A-86929 exhibits 20-fold higher (nanomolar) affinity for D1 and Dopamine-5 (D5) receptors when compared with the D-2 receptor and exhibits full agonist efficacy on D1-stimulated cAMP formation. ${ }^{117}$ A-86929 is also over 400 times more selective for dopamine D1 than D2 receptors. ${ }^{118}$ Both DAS-431 and A-86929 produced contralateral rotation in rats bearing unilateral 6-hydroxydopamine lesions and improve the behavioral disability scores and increased locomotor activity in the 1-methyl-4-phenyl-1,2,3,6-tetrahydropyridine (MPTP) marmoset model of Parkinson's disease. When administered chronically, A-86929 significantly improved disability scores during the duration of the study. ${ }^{117,118}$ DAS-431 has also been reported to reverse haloperidol-induced cognitive deficits such as spatial working memory and object working memory in monkeys, suggesting that it may be an effective treatment for the cognitive dysfunction associated with aging and disease. ${ }^{19}$

Preclinical studies showed that DAS-431 could attenuate the ability of cocaine to induce cocaine-seeking behavior and does not induce cocaine-seeking behavior in a rodent model of cocaine craving and relapse. ${ }^{120} \mathrm{In}$ human cocaine abusers, intravenous DAS-431 reduces cocaine craving and other cocaine-induced subjective effects. The results of animal abuse liability studies in- dicate that DAS-431 is unlikely to have abuse potential in man. ${ }^{121}$

As the first full dopamine D1 receptor agonist to show efficacy in improving Parkinson's disease and cognitive function and to reduce the craving and subjective effects of cocaine in cocaine abusers, DAS-431 represents an important tool to understand the pharmacotherapeutic potential of DA-1 receptor agonists in different pathological conditions including cognitive function.

\section{IMPLICATIONS FOR THE TREATMENT OF COGNITIVE DYSFUNCTION IN SCHIZOPHRENIA}

The study of cognitive dysfunction associated with impairment of the DPLFC has been one of the hallmarks in schizophrenia research. ${ }^{121-126}$ Over the last two to three decades, a growing number of studies on DLPF cognitive function ${ }^{127-129}$ and functional neuroimaging ${ }^{130-137}$ consistently revealed significant abnormalities in patients with schizophrenia. Exaggerated mesolimbic dopaminergic transmission has been proposed as the primary mechanism that contributes to the presence of positive symptoms such as delusions and hallucinations. This dopaminergic deregulation, however, does not seem to explain the prominent cognitive difficulties observed in patients with schizophrenia. Instead, more conclusive evidence suggests that the cognitive difficulties and negative symptoms (e.g., blunted affect, lack of motivation, poverty of speech, avolition, etc.) present in schizophrenia are related to a decreased connectivity and reduced functional activity of the mesocortical afferents innervating the DLPFC. ${ }^{138,139}$

Dysfunction in prefrontal activation during working memory tasks in patients with schizophrenia has been reported by number of groups indicating that the working memory deficits are most likely related to the decreased connectivity and reduced activity of the mesocortical system. $^{132,139-142}$ From a molecular pharmacological perspective, a reduction in presynaptic activity in the mesocortical dopaminergic system would decrease the input into postsynaptic sites with ensuing increase in the number or the affinity in postsynaptic receptors. In this context, when compared with control subjects, either a significant decrease or increase in the number of DA-1 receptors in the DLPFC of patients with schizophrenia was reported in studies using positron emission tomography ${ }^{143,144}$ and both changes have been associated with impaired cognition. The increase in DA-1 receptors strongly predicted poor performance in N-Back task, a reliable test of working memory. ${ }^{144}$

Pharmacological intervention aiming at increasing synaptic dopamine in the synaptic cleft or activating directly the DA-1 receptor in the prefrontal cortex may represent a useful tool to target DLPFC mechanisms and 
improve working memory and other cognitive deficits in patients with schizophrenia. Dopaminomimetic drugs (e.g., stimulants), however, may also produce a number of unwanted effects (i.e., worsening of psychosis, motor side effects) due to their effect on mesolimbic and nigrostriatal systems other than on the Me-DA pathway. The use of medications that specifically target the Me-DA system without acting on the other dopaminergic pathways may provide new avenues in the treatment of cognitive dysfunction in schizophrenia. This fact, coupled to the recent findings that patients with schizophrenia showed similar COMT allelic variations as in normal volunteers, and that genetic variation in this gene also predicts performance on tests of cognitive function, points toward a more targeted, genotype-based pharmacology for the treatment of cognitive disorders in schizophrenia. $^{74}$

Blockade of the catabolic mechanisms involved in DA regulation in the frontal cortex by inhibition of COMT may result in a very circumscribed and selective increase of dopamine in the frontal cortex without affecting subcortical regions $^{145}$ and represent another pharmacological mechanism for improving cortical cognitive function in schizophrenia.

The fact that modafinil, a drug used for the treatment of daytime sleepiness is also able to increase significantly extracellular dopamine in the prefrontal cortex ${ }^{97}$ and to enhance short-term working memory in experimental animals may also lead to expanded strategies with this medication for the treatment of cognitive dysfunction in schizophrenia. ${ }^{146}$ Modafinil proved to have a low side-effect profile and limited clinically relevant drug interactions, making this drug even more interesting form the perspective of its use in a combined therapeutic strategy with antipsychotics and other medications regularly prescribed in schizophrenia.

Early neuropsychological studies showed that an acute dose of dextroamphetamine, which increases dopamine levels in the DLPFC, has positive effects on affect and cognition in schizophrenic patients. However, because of its potential negative effects on psychosis, abnormal movements and behavior secondary to its effect on subcortical areas, the authors did not advocate the use of amphetamine as a routine clinical treatment of cognition problems in schizophrenia. ${ }^{147}$ In the last few years, the specific NE reuptake inhibitors (e.g., atomoxetine) have been shown also to be effective in increasing extracellular dopamine concentrations in the DLPFC without effects on subcortical dopaminergic systems ${ }^{104}$ and, hence, with no psychotomimetic effect or abuse potential. This very specific pharmacological action led to the development of this drug as a tool for the treatment of inattentiveness in attention deficit spectrum disorders. ${ }^{102,103}$ However, its spectrum of pharmacological action makes atomoxetine also a potential candidate to treat individu- als with working memory difficulties including schizophrenia, mood disorders, and cognitive deficits of different origin. It is to be expected that, similar to the effect of stimulants in the DLPFC, ${ }^{147}$ atomoxetine administration should result in an enhanced performance on WCST and improved activation in the DLPFC.

The evidence that impairment in cognitive function is connected with a deficit in the dopaminergic input to the DA-1 receptors in the DLPFC ${ }^{111}$ opened new avenues for the development of specific dopaminergic agonists with activity on the DA-1 receptors. ${ }^{116}$ Even though no available compounds exist for routine clinical trials, recent phase I and phase II trials with DAS-431, a DA-1 agonist that is delivered by intravenous route, provides future options for more comprehensive clinical studies with direct DA-1 compounds with agonistic action. Changes in the number of DA-1 receptors in the PFC in patients with schizophrenia, irrespective of their medication status, ${ }^{143,144}$ and their association with impaired performance in tests that measure working memory, ${ }^{144}$ supports the critical role of these receptors in cognitive control in schizophrenia. Drugs with DA-1 receptor agonistic activity would be of major interest for the treatment of the cognitive deficits of schizophrenia, and could be administered in conjunction with selective DA-2 antagonists for the combined treatment of positive and negative symptoms of schizophrenia.

\section{CONCLUSIONS}

The understanding of the pathophysiological mechanisms involved in the cognitive deficits observed in schizophrenia provided new grounds for the development of therapeutic strategies aiming at improving the DLPFC function. Preclinical studies identified a number of Food and Drug Administration (FDA)-approved drugs able to specifically regulate dopaminergic transmission in the terminals of the mesolimbic dopaminergic system

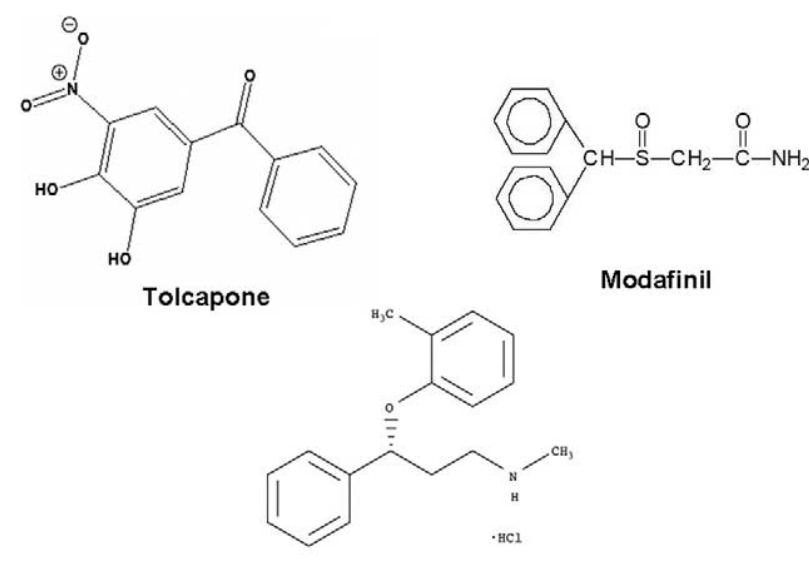

Atomoxetine

FIG. 1. FDA-approved drugs with selective prodopaminergic action at the level of the dorsolateral prefrontal cortex. 


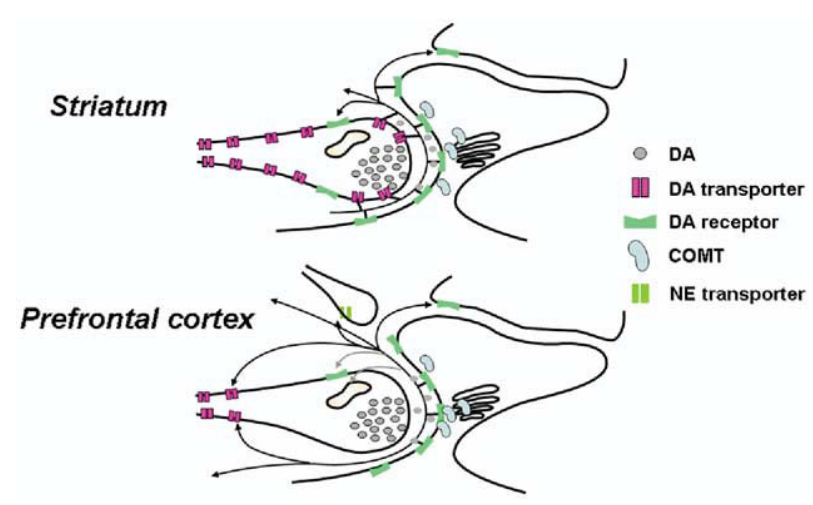

FIG. 2. Mesocortical dopamine terminals in the prefrontal cortex lack specific dopamine reuptake sites.

without affecting the neurotransmission on subcortical systems (see FIGS. 1 and 2). The ability of these compounds to improve cognitive function by increasing DA load to the DLPFC without stimulant-like effects provides an example of targeted pharmacology for the treatment of cognitive deficits in schizophrenia as well as other illnesses in which the DPLFC function is compromised. On the other hand, the preliminary evidence indicating that the effect of these drugs may be modified by interactions with the COMT genotype, the main catabolic mechanism in the prefrontal cortex, also illustrates the this new pharmacological approach may be also genotype-based. ${ }^{92,100,112,126,146}$

\section{REFERENCES}

1. Goldberg TE, Weinberger D. Probing prefrontal function in schizophrenia with neuropsychological paradigms. Schizophr Bull 14:179-183, 1988.

2. Da Prada M, Zurcher G, Kettler R, Colzi A. New therapeutic strategies in Parkinson's disease: inhibition of MAO-B by Ro 19-6327 and of COMT by Ro 40-7592. New York: Plenum, 1991.

3. Desimone R, Duncan J. Neural mechanisms of selective visual attention. Апnи Rev Neurosci 18:193-222, 1995.

4. Badre D, Wagner A. Selection, integration, and conflict monitoring; assessing the nature and generality of prefrontal cognitive control mechanisms. Neuron 41:473-487, 2004.

5. Lewis DA, Anderson S. The functional architecture of the prefrontal cortex and schizophrenia. Psychol Med 25:887-894, 1995.

6. Lewis DA. The catecholaminergic innervation of primate prefrontal cortex. J Neural Transm Suppl 36:179-200, 1992.

7. Curtis CE, D'Esposito M. The effects of prefrontal lesions on working memory performance and theory. Cogn Affect Behav Neurosci 4:528-539, 2004.

8. Smiley JF, Goldman-Rakic P. Silver-enhanced diaminobenzidine-sulfide (SEDS): a technique for high-resolution immunoelectron microscopy demonstrated with monoamine immunoreactivity in monkey cerebral cortex and caudate. J Histochem Cytochem 41:1393-1404, 1993.

9. Gao WJ, Krimer LS, Goldman-Rakic P. Presynaptic regulation of recurrent excitation by D1 receptors in prefrontal circuits. Proc Natl Acad Sci USA 98:295-300, 2001.

10. Arnsten A. Catecholamine regulation of the prefrontal cortex. J Psychopharmacol 11:151-162, 1997.

11. Elliott R, Sahakian BJ, Matthews K, Bannerjea A, Rimmer J, Robbins TW. Effects of methylphenidate on spatial working memory and planning in healthy young adults. Psychopharmacology (Berl ) 131:196-206, 1997.
12. Nielsen EB, Scheel-Kruger J. Central nervous system stimulants: neuropharmacological mechanisms. Psychopharmacol Ser 4:5772, 1988.

13. Seeman P, Madras B. Anti-hyperactivity medication: methylphenidate and amphetamine. Mol Psychiatry 3:386-396, 1998.

14. Keefe RS, Silva SG, Perkins DO, Lieberman J. The effects of atypical antipsychotic drugs on neurocognitive impairment in schizophrenia: a review and meta-analysis. Schizophr Bull 25: 201-222, 1999.

15. Green MF, Marshall BD Jr, Wirshing WC, Ames D, Marder SR, McGurk S, et al. Does risperidone improve verbal working memory in treatment-resistant schizophrenia? Am J Psychiatry 154: 799-804, 1997.

16. McGurk SR. The effects of clozapine on cognitive functioning in schizophrenia. J Clin Psychiatry 60:24-29, 1999.

17. Kapur S, Agid O, Mizrahi R, Li M. How antipsychotics workfrom receptors to reality. NeuroRx 3:10-21, 2006.

18. Ichikawa J, Kuroki T, Dai J, Meltzer H. Effect of antipsychotic drugs on extracellular serotonin levels in rat medial prefrontal cortex and nucleus accumbens. Eur J Pharmacol 35:163-171, 1998.

19. Goff DC, Tsai G, Manoach DS, Coyle J. Dose-finding trial of D-cycloserine added to neuroleptics for negative symptoms in schizophrenia. Am J Psychiatry 52:1213-1215, 1995.

20. Goff DC, Herz L, Posever T, Shih V, Tsai G, Henderson DC, et al. A six-month, placebo-controlled trial of D-cycloserine coadministered with conventional antipsychotics in schizophrenia patients. Psychopharmacology (Berl) 179:144-150, 2005.

21. Rosse RB, Fay-McCarthy M, Kendrick K, Davis RE, Deutsch S. D-cycloserine adjuvant therapy to molindone in the treatment of schizophrenia. Clin Neuropharmacol 19:444-450, 1996.

22. Rosse RB, Schwartz BL, Davis RE, Deutsch S. An NMDA intervention strategy in schizophrenia with "low-dose" milacemide. Clin Neuropharmacol 14:268-272, 1991.

23. Ingvar M, Ambros-Ingerson J, Davis M, Granger R, Kessler M, Rogers GA, et al. Enhancement by an ampakine of memory encoding in humans. Exp Neurol 146:553-559, 1997.

24. Koob GF. Hedonic valence, dopamine and motivation. Mol Psychiatry 1:186-189, 1996.

25. Braver TS, Barch DM, Cohen JD. Cognition and control in schizophrenia: a computational model of dopamine and prefrontal function. Biol Psychiatry 46:312-328, 1999.

26. Sawaguchi T, Goldman-Rakic P. The role of D1-dopamine receptor in working memory: local injections of dopamine antagonists into the prefrontal cortex of rhesus monkeys performing an oculomotor delayed-response task. J Neurophysiol 71:515-528, 1994.

27. Fuster JM. The prefrontal cortex: anatomy, physiology and neuropsychology of the frontal lobe. Vol 71. Philadelphia: Lippincott-Raven Publishers, 1997.

28. Bannon MJ, Roth R. Pharmacology of mesocortical dopamine neurons. Pharmacol Rev 35:53-68, 1983

29. Thierry AM, Tassin JP, Blanc G, Glowinski J. Selective activation of mesocortical DA system by stress. Nature 263:242-244, 1976.

30. Mantz J, Thierry AM, Glowinski J. Effect of noxious tail pinch on the discharge rate of mesocortical and mesolimbic dopamine neurons: selective activation of the mesocortical system. Brain Res 476:377-381, 1989.

31. Garris PA, Collins LB, Jones SR, Wightman RM. Evoked extracellular dopamine in vivo in the medial prefrontal cortex. $\mathrm{J} \mathrm{Neu}$ rochem 61:637-647, 1993.

32. Garris PA, Wightman RM. Distinct pharmacological regulation of evoked dopamine efflux in the amygdala and striatum of the rat in vivo. Synapse 20:269-279, 1995.

33. Sharp T, Zetterstrom T, Ungerstedt U. An in vivo study of dopamine release and metabolism in rat brain regions using intracerebral dialysis. J Neurochem 47:113-122, 1986.

34. Chiodo LA, Bannon MJ, Grace AA, Roth RH, Bunney BS. Evidence for the absence of impulse-regulating somatodendritic and synthesis-modulating nerve terminal autoreceptors on subpopulations of mesocortical dopamine neurons. Neuroscience 12:1-16, 1984. 
35. Nicholson C. Interaction between diffusion and Michaelis-Menten uptake of dopamine after iontophoresis in striatum. Biophys $J$ 68:1699-1715, 1995

36. Giros B, Jaber M, Jones SR, Wightman RM, Caron MG. Hyperlocomotion and indifference to cocaine and amphetamine in mice lacking the dopamine transporter. Nature 379:606-612, 1996.

37. Carboni E, Tanda GL, Frau R, Di Chiara G. Blockade of the noradrenaline carrier increases extracellular dopamine concentrations in the prefrontal cortex: evidence that dopamine is taken up in vivo by noradrenergic terminals. J Neurochem 55:1067-1070, 1990.

38. Cenci MA, Kalen P, Mandel RJ, Bjorklund A. Regional differences in the regulation of dopamine and noradrenaline release in medial frontal cortex, nucleus accumbens and caudate-putamen: a microdialysis study in the rat. Brain Res 581:217-228, 1992.

39. Moghaddam B, Bunney B. Differential effect of cocaine on extracellular dopamine levels in rat medial prefrontal cortex and nucleus accumbens: comparison to amphetamine. Synapse 4:156-161, 1989.

40. Karoum F, Chrapusta SJ, Egan M. 3-Methoxytyramine is the major metabolite of released dopamine in the rat frontal cortex: reassessment of the effects of antipsychotics on the dynamics of dopamine release and metabolism in the frontal cortex, nucleus accumbens, and striatum by a simple two pool model. J Neurochem 63:972-979, 1994.

41. Di Chiara G, Tanda GL, Frau R, Carboni E. Heterologous monoamine reuptake: lack of transmitter specificity of neuron-specific carriers. Neurochem Int 20 [Suppl]:231S-235S, 1992.

42. Moron JA, Brockington A, Wise RA, Rocha BA, Hope B. Dopamine uptake through the norepinephrine transporter in brain regions with low levels of the dopamine transporter: evidence from knock-out mouse lines. J Neurosci 22:389-395, 2002.

43. Mundorf ML, Joseph JD, Austin CM, Caron MG, Wightman R. Catecholamine release and uptake in the mouse prefrontal cortex. J Neurochem 79:130-142, 2001.

44. Paspalas CD, Goldman-Rakic P. Microdomains for dopamine volume neurotransmission in primate prefrontal cortex. J Neurosci 24:5292-5300, 2004.

45. Axelrod J, Tomchick R. Enzymatic O-methylation of epinephrine and other catechols. J Biol Chem 233:702-705, 1958.

46. Salminen M, Lundstrom K, Tilgmann C, Savolainen R, Kalkkinen N, Ulmanen I. Molecular cloning and characterization of rat liver catechol-O-methyltransferase. Gene 93:241-247, 1990.

47. Bertocci B, Miggiano V, Da Prada M, Dembic Z, Lahm HW, Malherbe P. Human catechol-O-methyltransferase: cloning and expression of the membrane-associated form. Proc Natl Acad Sci USA 88:1416-1420, 1991.

48. Lundstrom K, Salminen M, Jalanko A, Savolainen R, Ulmanen I. Cloning and characterization of human placental catechol-Omethyltransferase cDNA. DNA Cell Biol 10:181-189, 1991.

49. Lotta T, Vidgren J, Tilgmann C, Ulmanen I, Melen K, Julkunen $\mathrm{I}$, et al. Kinetics of human soluble and membrane-bound catechol O-methyltransferase: a revised mechanism and description of the thermolabile variant of the enzyme. Biochemistry 34:4202-4210, 1995.

50. Lundstrom K, Tenhunen J, Tilgmann C, Karhunen T, Panula P, Ulmanen I. Cloning, expression and structure of catechol-Omethyltransferase. Biochim Biophys Acta 1251:1-10, 1995.

51. Grossman MH, Emanuel BS, Budarf M. Chromosomal mapping of the human catechol-O-methyltransferase gene to 22q11.1q11.2. Genomics 12:822-825, 1992.

52. Winqvist R, Lundstrom K, Salminen M, Laatikainen M, Ulmanen I. The human catechol-O-methyltransferase (COMT) gene maps to band q11.2 of chromosome 22 and shows a frequent RFLP with BglI. Cytogenet Cell Genet 59:253-257, 1992.

53. Gogos J, Morgan M, Luine V, Santha M, Ogawa S, Pfaff D, et al. Catechol-O-methyltransferase-deficient mice exhibit sexually dimorphic changes in catecholamine levels and behavior. Proc Natl Acad Sci USA 95:9991-9996, 1998.

54. Huotari M, Gogos JA, Karayiorgou M, Koponen O, Forsberg M, Raasmaja A, et al. Brain catecholamine metabolism in catecholO-methyltransferase (COMT)-deficient mice. Eur J Neurosci 15: 246-256, 2002.
55. Matsumoto M, Weickert CS, Beltaifa S, Kolachana B, Chen J, Hyde TM, et al. Catechol O-methyltransferase (COMT) mRNA expression in the dorsolateral prefrontal cortex of patients with schizophrenia. Neuropsychopharmacology 28:1521-1530, 2003.

56. Lewis DA, Melchitzky DS, Sesack SR, Whitehead RE, Auh S, Sampson A. Dopamine transporter immunoreactivity in monkey cerebral cortex: regional, laminar, and ultrastructural localization. J Comp Neurol 432:119-136, 2001.

57. Mazei MS, Pluto CP, Kirkbride B, Pehek EA. Effects of catecholamine uptake blockers in the caudate-putamen and subregions of the medial prefrontal cortex of the rat. Brain Res 936: $58-67,2002$.

58. Sesack SR, Hawrylak VA, Melchitzky DS, Lewis DA. Dopamine innervation of a subclass of local circuit neurons in monkey prefrontal cortex: ultrastructural analysis of tyrosine hydroxylase and parvalbumin immunoreactive structures. Cereb Cortex 8:614-622, 1998.

59. Wayment HK, Schenk JO, Sorg BA. Characterization of extracellular dopamine clearance in the medial prefrontal cortex: role of monoamine uptake and monoamine oxidase inhibition. $\mathrm{J} \mathrm{Neu}$ rosci 21:35-44, 2001.

60. Weinshilboum R, Raymond F. Variations in catechol-O-methyltransferase activity in inbred strains of rats. Neuropharmacology 16:703-706, 1977.

61. Spielman RS, Weinshilboum R. Genetics of red cell COMT activity: analysis of thermal stability and family data. Am J Med Genet 10:279-290, 1981.

62. Boudikova B, Szumlanski C, Maidak B, Weinshilboum R. Human liver catechol-O-methyltransferase pharmacogenetics. Clin Pharmacol Ther 48:381-389, 1990.

63. Aksoy S, Klener J, Weinshilboum R. Catechol O-methyltransferase pharmacogenetics: photoaffinity labelling and western blot analysis of human liver samples. Pharmacogenetics 3:116-122, 1993.

64. Reilly DK, Rivera-Calimlim L, Van Dyke D. Catechol-O-methyltransferase activity: a determinant of levodopa response. Clin Pharmacol Ther 28:278-286, 1980.

65. Campbell NR, Dunnette JH, Mwaluko G, Van Loon J, Weinshilboum RM. Platelet phenol sulfotransferase and erythrocyte catechol-O-methyltransferase activities: correlation with methyldopa metabolism. Clin Pharmacol Ther 35:55-63, 1984.

66. Goldstein M, Lieberman A. The role of the regulatory enzymes of catecholamine synthesis in Parkinson's disease. Neurology 42 [Suppl 4]:41-48, 1992.

67. Chen J, Lipska BK, Halim N, Ma QD, Matsumoto M, Melhem S et al. Functional analysis of genetic variation in catechol-O-methyltransferase (COMT): effects on mRNA, protein, and enzyme activity in postmortem human brain. Am J Hum Genet 75:807821, 2004.

68. Kimberg DY, D'Esposito M, Farah M. Effects of bromocriptine on human subjects depend on working memory capacity. Neuroreport 8:3581-3585, 1997.

69. Williams GV, Goldman-Rakic PS. Modulation of memory fields by dopamine D1 receptors in prefrontal cortex. Nature 376:572575, 1995.

70. Arnsten AF, Goldman-Rakic P. Analysis of $\alpha-2$ adrenergic agonist effects on the delayed nonmatch-to-sample performance of aged rhesus monkeys. Neurobiol Aging 11:583-590, 1990.

71. Arnsten AF, Cai JX, Murphy BL, Goldman-Rakic P. Dopamine D1 receptor mechanisms in the cognitive performance of young adult and aged monkeys. Psychopharmacology (Berl ) 116:143151, 1994.

72. Arnsten AF, Goldman-Rakic P. Noise stress impairs prefrontal cortical cognitive function in monkeys: evidence for a hyperdopaminergic mechanism. Arch Gen Psychiatry 55:362-368, 1998.

73. Mattay VS, Callicott JH, Bertolino A, Heaton I, Frank JA, Coppola $\mathrm{R}$, et al. Effects of dextroamphetamine on cognitive performance and cortical activation. Neuroimage 12:268-275, 2000.

74. Egan MF, Goldberg TE, Kolachana BS, Callicott JH, Mazzanti CM, Straub RE, et al. Effect of COMT Val108/158 Met genotype on frontal lobe function and risk for schizophrenia. Proc Natl Acad Sci USA 98:6917-6922, 2001. 
75. Diaz-Asper CM, Goldberg TE. COMT polymorphism and prefrontal cognitive function. NeuroRx 3:97-105, 2006.

76. Kneavel M, Gogos J, Karayiorgou K, Luine V. Interaction of COMT gene deletion and environment on cognition. Proceedings of the Society for Neuroscience 30th Annual Meeting, New Orleans, LA, Abstract 571.20, 2000.

77. Guldberg HC, Marsden CA. Catechol-O-methyl transferase: pharmacological aspects and physiological role. Pharmacol Rev 27:135-206, 1975.

78. Zurcher G, Colzi A, Da Prada M. Ro 40-7592: inhibition of COMT in rat brain and extracerebral tissues. J Neural Transm Suppl 32:375-380, 1990.

79. Zurcher G, Keller HH, Kettler R, Borgulya J, Bonetti EP, Eigenmann R, et al. Ro 40-7592, a novel, very potent, and orally active inhibitor of catechol-O-methyltransferase: a pharmacological study in rats. Adv Neurol 53:497-503, 1990.

80. Zurcher G, Dingemanse J, Da Prada M. Ro-40-7592, a potent inhibitor of extracerebral and brain catechol-O-methyltransferase: preclinical and clinical findings. Rome: John Libbey S.R.L., 1991.

81. Ceravolo R, Piccini P, Bailey DL, Jorga KM, Bryson H, Brooks DJ. 18F-dopa PET evidence that tolcapone acts as a central COMT inhibitor in Parkinson's disease. Synapse 43:201-207, 2002.

82. Stahl SM. Finding what you are not looking for: strategies for developing novel treatments in psychiatry. NeuroRx 3:3-9, 2006.

83. Khromova I, Rauhala P, Zolotov N, M"nnist" P. Tolcapone, an inhibitor of catechol O-methyltransferase, counteracts memory deficits caused by bilateral cholinotoxin lesions of the nucleus basalis of Meynert. Neuroreport 6:1219-1222, 1995.

84. Liljequist R, Haapalinna A, Ahlander M, Li YH, Mannisto PT. Catechol O-methyltransferase inhibitor tolcapone has minor influence on performance in experimental memory models in rats. Behav Brain Res 82:195-202, 1997.

85. Kaakkola S, Gordin A, J"rvinen M, Wikberg T, Schultz E, Nissinen E, et al. Effect of a novel catechol-O-methyltransferase inhibitor, nitecapone, on the metabolism of L-DOPA in healthy volunteers. Clin Neuropharmacol 13:436-447, 1990.

86. Ker"nen T, Gordin A, Harjola VP, Karlsson M, Korpela K, Pentik"inen PJ, et al. The effect of catechol-O-methyl transferase inhibition by entacapone on the pharmacokinetics and metabolism of levodopa in healthy volunteers. Clin Neuropharmacol 16:145-156, 1993.

87. Gasparini M, Fabrizio E, Bonifati V, Meco G. Cognitive improvement during Tolcapone treatment in Parkinson's disease. J Neural Transm 104:887-894, 1997.

88. Fava M, Rosenbaum JF, Kolsky A, Alpert JE, Nierenberg AA, Spillman M, et al. Open study of the catechol-o-methyltransferase inhibitor tolcapone in major depressive disorder. J Clin Psychopharm 19:329-335, 1999.

89. Apud JA, Mattay V, Das B, Iudicello J, Akbar N, Egan M, et al. COMT genotype and cognition: effects of tolcapone on working memory and fMRI in normal volunteers. Proceedings of the 60th Annual Meeting of the Society of Biological Psychiatry, Atlanta, GA, Abstract 18, 2005.

90. Arnulf I, Homeyer P, Garma L, Whitelaw WA, Derenne J Modafinil in obstructive sleep apnea-hypopnea syndrome: a pilot study in 6 patients. Respiration 64:159-161, 1997.

91. Besset A, Chetrit M, Carlander B, Billiard M. Use of modafinil in the treatment of narcolepsy: a long term follow-up study. Neurophysiol Clin 26:60-66, 1996.

92. Billiard M, Merle C, Carlander B, Ondze B, Alvarez D, Besset A. Idiopathic hypersomnia. Psychiatry Clin Neurosci 52:125-129, 1998.

93. Duteil J, Rambert FA, Pessonnier J, Hermant JF, Gombert R, Assous E. Central $\alpha 1$-adrenergic stimulation in relation to the behaviour stimulating effect of modafinil; studies with experimental animals. Eur J Pharmacol 180:49-58, 1990.

94. Pierard C, Satabin P, Lagarde D, Barrere B, Guezennec CY, Menu JP, et al. Effects of a vigilance-enhancing drug, modafinil, on rat brain metabolism: a 2D COSY 1H-NMR study. Brain Res 693:251-256, 1995.

95. Perez de la Mora M, Aguilar-Garcia A, Ramon-Frias T, Ramirez-
Ramirez R, Mendez-Franco J, Rambert F, et al. Effects of the vigilance promoting drug modafinil on the synthesis of GABA and glutamate in slices of rat hypothalamus. Neurosci Lett 259:181-185, 1999.

96. Ferraro L, Antonelli T, Tanganelli S, O'Connor WT, Perez de la Mora M, Mendez-Franco J, et al. The vigilance promoting drug modafinil increases extracellular glutamate levels in the medial preoptic area and the posterior hypothalamus of the conscious rat: prevention by local GABAA receptor blockade. Neuropsychopharmacology 20:346-356, 1999.

97. Wisor JP, Nishino S, Sora I, Uhl GH, Mignot E, Edgar DM. Dopaminergic role in stimulant-induced wakefulness. $J$ Neurosci 21:1787-1794, 2001.

98. de Saint Hilaire Z, Orosco M, Rouch C, Blanc G, Nicolaidis S. Variations in extracellular monoamines in the prefrontal cortex and medial hypothalamus after modafinil administration: a microdialysis study in rats. Neuroreport 12:3533-3537, 2001.

99. Beracochea D, Cagnard B, Celerier A, le Merrer J, Peres M, Pierard C. First evidence of a delay-dependent working memoryenhancing effect of modafinil in mice. Neuroreport 12:375-378, 2001.

100. Turner DC, Robbins TW, Clark L, Aron AR, Dowson J, Sahakian BJ. Cognitive enhancing effects of modafinil in healthy volunteers. Psychopharmacology (Berl) 165:26026-26019, 2003.

101. Tafti M, Dauvilliers Y. Pharmacogenomics in the treatment of narcolepsy. Pharmacogenomics 4:23-33, 2003.

102. Kratochvil CJ, Vaughan BS, Harrington MJ, Burke W. Atomoxetine: a selective noradrenaline reuptake inhibitor for the treatment of attention-deficit/hyperactivity disorder. Expert Opin Pharmacother 4:1165-1174, 2003.

103. Wong D, Threlkeld PG, Best KL, Bymaster FP. A new inhibitor of norepinephrine uptake devoid of affinity for receptors in rat brain. J Pharmacol Exp Ther 222:61-65, 1982.

104. Bymaster FP, Katner JS, Nelson DL, Hemrick-Luecke SK, Threlkeld PG, Heiligenstein JH, et al. Atomoxetine increases extracellular levels of norepinephrine and dopamine in prefrontal cortex of rat: a potential mechanism for efficacy in attention deficit/hyperactivity disorder. Neuropsychopharmacology 27:699-711, 2002.

105. Stahl SM. Selective NRIs are smart drugs: exploiting regionally selective actions on both dopamine and norepinephrine to enhance cognition. J Clin Psychiatry 64:110-111, 2003.

106. Michelson D, Allen AJ, Busner J, Casat C, Dunn D, Kratochvil C, et al. Once-daily atomoxetine treatment for children and adolescents with attention deficit hyperactivity disorder: a randomized, placebo-controlled study. Am J Psychiatry 159:1896-1901, 2002.

107. Pierce RC, Kalivas P. A circuitry model of the expression of behavioral sensitization to amphetamine-like psychostimulants. Brain Res Brain Res Rev 25:192-216, 1997.

108. Mattay VS, Goldberg TE, Fera F, Hariri AR, Tessitore A, Egan MF, et al. Catechol O-methyltransferase val158-met genotype and individual variation in the brain response to amphetamine. Proc Natl Acad Sci USA 100:6186-6191, 2003.

109. Castner SA, Goldman-Rakic PS, Williams GV. Animal models of working memory: insights for targeting cognitive dysfunction in schizophrenia. Psychopharmacology (Berl) 174:111-125, 2004.

110. Goldman-Rakic PS, Lidow MS, Smiley JF, Williams MS. The anatomy of dopamine in monkey and human prefrontal cortex. J Neural Transm Suppl 36:163-177, 1992.

111. Granon S, Passetti F, Thomas KL, Dalley JW, Everitt BJ, Robbins T. Enhanced and impaired attentional performance after infusion of D1 dopaminergic receptor agents into rat prefrontal cortex. J Neurosci 20:1208-1215, 2000.

112. Didriksen M. Effects of antipsychotics on cognitive behaviour in rats using the delayed non-match to position paradigm. Eur J Pharmacol 281:241-250, 1995.

113. Mattay VS, Berman KF, Ostrem JL, Esposito G, Van Horn JD, Bigelow LB, et al. Dextroamphetamine enhances "neural network-specific" physiological signals: a positron-emission tomography rCBF study. J Neurosci 16:4816-4822, 1996.

114. Davidson M, Harvey PD, Bergman RL, Powchik P, Kaminsky R, Losonczy MF, et al. Effects of the D-1 agonist SKF-38393 combined with haloperidol in schizophrenic patients. Arch Gen Psychiatry 47:190-191, 1990. 
115. Steele TD, Hodges DB Jr, Levesque TR, Locke KW. D1 agonist dihydrexidine releases acetylcholine and improves cognitive performance in rats. Pharmacol Biochem Behav 58:477-483, 1997.

116. Michaelides MR, Hong Y, DiDomenico S Jr, Asin KE, Britton DR, Lin $\mathrm{CW}$, et al. (5aR,11bS)-4,5,5a,6,7,11b-hexahydro-2-propyl-3thia-5-azacyclopent-1-ena[c]-phenanthrene-9,10-diol (A-86929): a potent and selective dopamine D1 agonist that maintains behavioral efficacy following repeated administration and characterization of its diacetyl prodrug (ABT-431). J Med Chem 38:3445-3447, 1995.

117. Shiosaki K, Jenner P, Asin KE, Britton DR, Lin CW, Michaelides $\mathrm{M}$, et al. ABT-431: the diacetyl prodrug of A-86929, a potent and selective dopamine D1 receptor agonist: in vitro characterization and effects in animal models of Parkinson's disease. J Pharmacol Exp Ther 276:150-160, 1996.

118. Giardina WJ, Williams M. Adrogolide HCl (ABT-431; DAS431), a prodrug of the dopamine D1 receptor agonist, A-86929: preclinical pharmacology and clinical data. CNS Drug Rev 7:305316, 2001.

119. Castner SA, Williams GV, Goldman-Rakic PS. Reversal of antipsychotic-induced working memory deficits by short-term dopamine D1 receptor stimulation. Science 287:2020-2022, 2000.

120. Self DW, Karanian DA, Spencer J. Effects of the novel D1 dopamine receptor agonist ABT-431 on cocaine self-administration and reinstatement. NY Acad Sci 909:133-144, 2000.

121. Haney M, Foltin RW, Fischman M. Effects of pergolide on intravenous cocaine self-administration in men and women. Psychopharmacology (Berl) 137:15-24, 1998.

122. Callicott JH, Weinberger DR. Neuropsychiatric dynamics: the study of mental illness using functional magnetic resonance imaging. Eur J Radiol 30:95-104, 1999.

123. Goldman-Rakic PS. The physiological approach: functional architecture of working memory and disordered cognition in schizophrenia. Biol Psychiatry 46:650-661, 1999.

124. Bunney WE, Bunney BG. Evidence for a compromised dorsolateral prefrontal cortical parallel circuit in schizophrenia. Brain Res Brain Res Rev 31:138-146, 2000.

125. Harvey PD. Conference report: The Seventh Biennial Mount Sinai conference on cognition in schizophrenia. Schizophr Bull 31:895-897, 2005.

126. Bowie CR, Harvey PD. Cognition in schizophrenia: impairments, determinants, and functional importance. Psychiatr Clin North Am 28:613-633, 2005.

127. Barch DM, Carter C. Selective attention in schizophrenia: relationship to verbal working memory. Schizophr Res 33:53-61, 1998.

128. Goldberg TE, Gold JM, Coppola R, Weinberger DR. Unnatural practices, unspeakable actions: a study of delayed auditory feedback in schizophrenia. Am J Psychiatry 154:858-860, 1997.

129. Park S, Holzman P. Schizophrenics show spatial working memory deficits. Arch Gen Psychiatry 49:975-982, 1992.

130. Andreasen NC, O'Leary DS, Cizadlo T, Arndt S, Rezai K, Ponto LL, et al. Schizophrenia and cognitive dysmetria: a positronemission tomography study of dysfunctional prefrontal-thalamiccerebellar circuitry. Proc Natl Acad Sci USA 93:9985-9990, 1996.

131. Berman KF, Torrey EF, Daniel DG, Weinberger D. Regional cerebral blood flow in monozygotic twins discordant and concordant for schizophrenia. Arch Gen Psychiatry 49:927-934, 1992.

132. Callicott JH, Ramsey NF, Tallent K, Bertolino A, Knable MB, Coppola $\mathrm{R}$, et al. Functional magnetic resonance imaging brain mapping in psychiatry: methodological issues illustrated in a study of working memory in schizophrenia. Neuropsychopharmacology 18:186-196, 1998.

133. Catafau AM, Parellada E, Lomena FJ, Bernardo M, Pavia J, Ros $\mathrm{D}$, et al. Prefrontal and temporal blood flow in schizophrenia: resting and activation technetium-99m-HMPAO SPECT patterns in young neuroleptic-naive patients with acute disease. $J$ Nucl Med 35:935-941, 1994.

134. Curtis VA, Bullmore ET, Brammer MJ, Wright IC, Williams SC, Morris RG, et al. Attenuated frontal activation during a verbal fluency task in patients with schizophrenia. Am J Psychiatry 155:1056-1063, 1998.

135. Kawasaki Y, Maeda Y, Suzuki M, Urata K, Higashima M, Kiba $\mathrm{K}$, et al. SPECT analysis of regional cerebral blood flow changes in patients with schizophrenia during the Wisconsin Card Sorting Test. Schizophr Res 10:109-116, 1993.

136. Weinberger DR, Berman KF, Zec RF. Physiologic dysfunction of dorsolateral prefrontal cortex in schizophrenia. I. Regional cerebral blood flow evidence. Arch Gen Psychiatry 43:114-124, 1986.

137. Weinberger DR, Berman KF, Torrey EF. Correlations between abnormal hippocampal morphology and prefrontal physiology in schizophrenia. Clin Neuropharmacol 15 [Suppl 1]:393A-394A, 1992.

138. Weinberger DR, Berman KF, Daniel DG. Mesoprefrontal cortical dopaminergic activity and prefrontal hypofunction in schizophrenia. Clin Neuropharmacol 15 [Suppl 1]:568A-569A, 1992.

139. Callicott JH, Bertolino A, Mattay VS, Langheim FJ, Duyn J, Coppola R, et al. Physiological dysfunction of the dorsolateral prefrontal cortex in schizophrenia revisited. Cereb Cortex 10: 1078-1092, 2000.

140. Manoach DS, Press DZ, Thangaraj V, Searl MM, Goff DC, Halpern E, et al. Schizophrenic subjects activate dorsolateral prefrontal cortex during a working memory task, as measured by fMRI. Biol Psychiatry 45:1128-1137, 1999.

141. Manoach DS, Gollub RL, Benson ES, Searl MM, Goff DC, Halpern E, et al. Schizophrenic subjects show aberrant fMRI activation of dorsolateral prefrontal cortex and basal ganglia during working memory performance. Biol Psychiatry 48:99-109, 2000.

142. Perlstein WM, Carter CS, Noll DC, Cohen J. Relation of prefrontal cortex dysfunction to working memory and symptoms in schizophrenia. Am J Psychiatry 158:1105-1113, 2001.

143. Okubo Y, Suhara T, Suzuki K, Kobayashi K, Inoue O, Terasaki $\mathrm{O}$, et al. Decreased prefrontal dopamine D1 receptors in schizophrenia revealed by PET. Nature 385:634-636, 1997.

144. Abi-Dargham A, Mawlawi O, Lombardo I, Gil R, Martinez D, Huang Y, et al. Prefrontal dopamine D1 receptors and working memory in schizophrenia. $J$ Neurosci 22:3708-3719, 2002.

145. Li YH, Wirth T, Huotari M, Laitinen K, MacDonald E, Mannisto PT. No change of brain extracellular catecholamine levels after acute catechol-O-methyltransferase inhibition: a microdialysis study in anaesthetized rats. Eur J Pharmacol 356:127-137, 1998.

146. Goldberg TE, Bigelow LB, Weinberger DR, Daniel DG, Kleinman JE. Cognitive and behavioral effects of the coadministration of dextroamphetamine and haloperidol in schizophrenia. Am J Psychiatry 148:78-84, 1991.

147. Daniel DG, Weinberger DR, Jones DW, Zigun JR, Coppola R, Handel S, et al. The effect of amphetamine on regional cerebral blood flow during cognitive activation in schizophrenia. $\mathrm{J} \mathrm{Neu-}$ rosci 11:1907-1917, 1991. 